\title{
Trabalho e juventude: entrevista com Maria Carla Corrochano
}

\begin{abstract}
Nesta entrevista, realizada por e-mail em julho de 2005, Maria Carla Corrochano falou a Juliana Breschigliari de seu percurso profissional e acadêmico e sobre alguns dos debates relacionados ao trabalho e à juventude no Brasil. Maria Carla Corrochano é graduada em Ciências Sociais, Mestre em Educação, Doutoranda em Sociologia da Educação pela USP e Assessora do Programa Juventude da ONG Ação Educativa.
\end{abstract}

Juliana Breschigliari - Você escolheu estudar e trabalhar com a questão do trabalho na juventude. Sabemos que os jovens compõem uma das faixas-etárias mais atingidas pelo desemprego, por exemplo. Fale um pouco sobre essa escolha.

Maria Carla Corrochano - Quando comecei a trabalhar com o tema juventude e trabalho, não foram apenas as taxas de desemprego que me motivaram. Poderia dizer que essa não era a questão central. Em 1997, quando escrevi meu projeto de mestrado, minha questão era compreender a experiência juvenil com as mudanças e também permanências no interior do espaço produtivo. Acreditava que, assim como demonstravam os estudos de gênero, também haveria questões específicas a discutir quando se tratava da categoria geração. Além disso, diante das aceleradas transformações que atravessavam o mundo do trabalho, a questão era saber o lugar do trabalho na vida dos jovens. Havia um debate muito presente, sobretudo a partir do estudo de Clauss Offe ${ }^{2}$, sobre a perda da centralidade da categoria trabalho, alguns outros estudos começavam a questionar a centralidade do trabalho em uma geração nascida sob a chamada crise da sociedade do trabalho, enfim... Tratava-se de investigar, para o caso brasileiro, se o trabalho seria ou não uma referência importante entre os jovens, que sentidos o trabalho assumia.

Juliana - Que outras especificidades o mundo do trabalho tem em relação ao universo juvenil hoje?

Maria Carla - Compreender as relações entre gerações no interior mesmo dos espaços de trabalho, a maneira como os jovens vivenciam suas experiências de trabalho e os sentidos atribuídos a ela são outras especificidades, para além das taxas de desemprego. Mas, se observarmos as taxas de desemprego, também aí temos questões específicas a serem observadas. Se considerarmos o desemprego enquanto uma construção social, cabe questionarmos o porquê das taxas mais elevadas de desemprego entre os jovens e o porquê do debate em torno do desemprego juvenil ganhar tanto destaque no espaço público. As taxas de desemprego entre mulheres e negros também são muito elevadas. Por que não ganham o espaço que o desemprego juvenil, sobretudo o dos jovens homens, ganha? Uma outra questão importante a debater diz respeito às próprias políticas públicas a serem construídas para esse grupo. Que políticas? E se considerarmos a diversidade tão presente entre os jovens, que políticas, para quais jovens?

Juliana - Há até pouco tempo, apostava-se muito na idéia de que quanto maior a escolaridade do jovem, maiores suas chances de entrada no mercado de trabalho. Como está essa relação entre escolaridade e empregabilidade atualmente?

1 Maria Carla Corrochano é autora/co-autora das seguintes publicações sobre juventude: Desemprego juvenil no Cone Sul: uma análise de década, Fundação Friedrich Ebert/ILDES, 2003. Elaboração participativa de projetos: um guia para jovens, Ação Educativa, 2002. Jovens olhares sobre o trabalho: um estudo dos jovens operários de São Bernardo do Campo, Faculdade de Educação da USP, 2001.

2 Offe, C. (1994). Capitalismo desorganizado. São Paulo: Brasiliense. 
Maria Carla - É inegável que esta geração é a mais escolarizada dos últimos anos. Análise do IPEA realizada a partir dos dados recentes da PNAD aponta o aumento da freqüência à escola e, para aqueles com idade entre 15 e 19 anos, uma diminuição na participação no mercado de trabalho, cuja explicação mais plausível parece ser a da preferência por continuar os estudos. A despeito disso, os dados indicam que os jovens com Ensino Médio incompleto e completo enfrentam as taxas mais altas de desemprego. Isto significa que completar o Ensino Fundamental e até mesmo o Ensino Médio não são garantias de conquistar uma vaga no mercado de trabalho. Ao mesmo tempo, as taxas de desemprego são mais baixas entre aqueles com baixa escolaridade. Mas a questão é o tipo de trabalho realizado por esses jovens com baixa escolaridade. Em geral, eles ocupam postos de trabalho mais precários e de baixa remuneração. Assim, os dados indicam que um maior nível de escolaridade é fundamental para a garantia de uma boa inserção no mercado.

De qualquer modo, maior escolaridade também não garante que o trabalho a ser realizado seja necessariamente melhor. Como as taxas de desemprego são muito elevadas, a exigência de maior escolaridade acaba muitas vezes se transformando em critério de desempate. Além disso, para além da escolaridade, outras questões parecem fundamentais para compreender as chances de entrada no mercado de trabalho. A indicação por exemplo. Entre os jovens, também ganha força o conhecido argumento da "falta de experiência" para conseguir uma vaga, destacado entre os mais diferentes perfis juvenis. Em resumo, se apenas maior escolaridade não garante inserção, as estatísticas deixam claro que ela se torna extremamente importante, sobretudo para um emprego de maior qualidade.

Juliana - Na sua pesquisa de mestrado, você entrevistou jovens operários de São Bernardo do Campo. Conte um pouco sobre como foi fazer essa pesquisa. Quais foram as dificuldades do trabalho de campo?

Maria Carla - No meu mestrado, fiz um estudo com jovens operários do setor de autopeças na cidade de São Bernardo do Campo. Em relação ao trabalho de campo, enfrentei as dificuldades comuns àqueles que desejam realizar uma pesquisa no interior do espaço de trabalho. Primeiramente, encontrar empresas que permitissem a realização da pesquisa. Não foi fácil... Das 15 empresas mapeadas, que tinham as características que desejávamos, apenas 3 permitiram a realização da pesquisa. Depois, como fazia as entrevistas em uma "salinha" na própria fábrica, tratava-se de convencer os jovens trabalhadores de que eu não tinha sido "enviada" pela própria empresa. Para isso, procurei passar o maior tempo possível no interior da fábrica. Almoçava com os jovens, assisti a muitos jogos de futebol, fui a alguns botecos na tentativa de construir uma relação de maior confiança. Só depois comecei as entrevistas. Ainda assim, quando estava na metade do trabalho de campo, ouvi comentários de que talvez tivesse alguma relação com o dono da empresa ou gerência. Mas aos poucos fui conquistando a confiança, sempre num processo lento.

Juliana - $\mathrm{O}$ que você destacaria dos depoimentos desses jovens ou das suas observações nas fábricas? Quais os sentidos do trabalho para os jovens?

Maria Carla - Especificamente em relação aos jovens, destacaria as ambigüidades percebidas. Embora as gerencias destacassem que estavam contratando mais jovens por considerá-los mais escolarizados, mais abertos às mudanças que estavam sendo implementadas no chão da fábrica, eram muito limitadas as reais possibilidades dos jovens interferirem nos processos. De fato, alguns estudos já vinham indicando a limitação da participação dos trabalhadores nos processos de inovação. Entre os jovens das empresas que investiguei, essa limitação era um pouco maior. Ao mesmo tempo, os jovens estavam sujeitos a muitos estereótipos tais como rebeldia, inconstância. Jovens que ainda estavam na fábrica na condição de aprendizes tinham muito pouco espaço para aprendizado de fato. Também havia questões referentes à relação entre gerações, sobretudo em razão do que seria mais importante: maior experiência ou maior escolaridade. 
Um outro aspecto que chamou muito a minha atenção foi a grande preocupação com o emprego. Ao serem questionados sobre o que seria mais importante em seu trabalho atual, a grande maioria dos jovens destacou, em primeiro lugar, o fato de estarem empregados. A realização profissional estava posta em segundo plano para a maioria deles. $O$ trabalho parecia extremamente importante e central, sobretudo porque reconheciam a dificuldade em encontrá-lo. Além disso, também percebemos que o trabalho tinha sentidos diversos entre os jovens: A possibilidade de tornar-se independente dos pais era algo comum entre todos, independentemente do nível de escolaridade, da renda, do sexo, do tipo de trabalho realizado. Apareceram também à possibilidade de comprar suas próprias coisas, de vivenciar a condição juvenil, o trabalho como necessidade, dignidade e realização pessoal. A depender do perfil, havia maior destaque para um ou outro sentido. Por exemplo: entre os jovens mais escolarizados, a possibilidade de realização pessoal pelo trabalho era maior. Para aqueles com mais baixa renda, a questão da necessidade aparecia com mais força. Isto não significa que não fosse possível observar entre os jovens de mais baixa renda um olhar para o trabalho como possibilidade de realização, mas ela ficava em segundo plano. De qualquer modo, foi importante perceber essa diversidade de sentidos do trabalho entre jovens e a relação desses sentidos com elementos de seu perfil.

Juliana - Conte um pouco do que você pretende investigar na sua pesquisa de doutorado.

Maria Carla - Em meu doutorado, pretendo me concentrar na análise de trajetórias juvenis em sua relação com o trabalho, o desemprego e a escola, bem como nos sentidos que lhes são atribuídos pelos próprios jovens, a partir de sua participação em iniciativas públicas na área do trabalho. Estou entrevistando jovens egressos do Programa Bolsa Trabalho, implementado pelo governo municipal na cidade de São Paulo entre os anos de 2001 e 2004. Estou realizando entrevistas em pelo menos dois distritos, conversando com jovens e seus familiares. Desde quando terminei meu mestrado, chamou muita atenção a forte preocupação dos jovens com o desemprego, ainda que todos os jovens entrevistados estivessem empregados. Como seria isso entre jovens à procura de trabalho ou inseridos precariamente no mercado de trabalho? Além disso, multiplicaram-se as iniciativas públicas dirigidas a jovens com o objetivo de encontrar saídas ao desemprego juvenil. Por um lado, a idéia de apoiar a inserção dos jovens; por outro, a de retardar seu ingresso no mercado de trabalho. Quero perceber como os próprios jovens e suas famílias estão vivendo essa situação e percebendo essas propostas. Que lugar trabalho e educação estão ocupando entre os jovens e suas famílias?

Juliana - Sabemos que muitos dos projetos ou programas dirigidos a jovens hoje - inclusive os projetos não-profissionalizantes - têm como objetivo a inserção dos jovens no mundo do trabalho ou a colocação no mercado de trabalho. Quais são as diferenças entre esses tipos de intervenção que existem?

Maria Carla - São muitas as intervenções e acho que não saberia falar das diferenças entre todas elas. Em nosso país, houve e ainda há uma tendência para a oferta de cursos profissionalizantes não apenas para jovens, mas também para adultos, com o objetivo de enfrentar o desemprego. Muitos desses programas já foram criticados por acabarem responsabilizando o próprio indivíduo pelo desemprego, ou seja, se o individuo está desempregado é porque lhe falta qualificação. Sabemos que não é isso. Acho que um outro debate interessante, resultado de diferentes intervenções, é se devemos retardar o quanto possível a entrada dos jovens no mercado de trabalho, priorizando a elevação da sua escolaridade e formação e reservando os escassos empregos para os adultos, ou se devemos contribuir para a inserção dos jovens no mercado de trabalho, proporcionando-lhes condições de gerar renda, muitas vezes imprescindível para suas famílias e para sua própria autonomia. Há programas que privilegiam o apoio à inserção, outros que privilegiam o retardamento. Também há algumas iniciativas que procuram fomentar o cooperativismo entre os jovens. Em todas elas, tenho percebido que as respostas muitas vezes se concentram na perspectiva da formação. Mas apenas a formação não consegue responder aos desafios do 
presente. Além disso, em grande parte dos casos, aposta-se em uma única saída. Mas se a questão do trabalho e da falta de trabalho tem se tornado um dilema entre tantos jovens e se considerarmos que a relação dos jovens com o trabalho é muito diversa, o ideal seria combinar diferentes alternativas. Não apenas incentivar o trabalho assalariado ou o retardamento do ingresso no mercado de trabalho, mas também o trabalho associativo e cooperativo; o trabalho social em áreas diversas, tais como saúde, educação, cultura, lazer, esporte, turismo, comunicação; a formação empreendedora, o acesso ao crédito, dentre outras.

Juliana - Que impacto você considera que esses projetos ou programas têm produzido? Quais os avanços obtidos até agora e quais os desafios que estão postos?

Maria Carla - Ainda é difícil avaliar os resultados das estratégias que vem sendo desenvolvidas, por serem muito emergentes. Este é um avanço. Nos últimos anos, despontaram várias iniciativas nas diferentes esferas do governo. Mas ainda é difícil avaliar resultados. O que podemos perceber, por exemplo, no caso de programas que procuram apoiar a inserção dos jovens no mercado de trabalho formal - tais como o Programa Primeiro Emprego, do Governo Federal, o Bolsa Trabalho Emprego, implementado na gestão municipal anterior, ou no Programa Jovem Cidadão - Meu Primeiro Trabalho, do governo do Estado de São Paulo - é que o número de empregos efetivamente gerado para jovens é muito baixo, quase irrisório. Evidente que há muitas razões para isso, como a dificuldade do próprio país em gerar empregos, mas falta muito comprometimento dos empresários. Além disso, quando se comprometem, caberia perguntar: que tipo de trabalho os jovens estarão desenvolvendo nas empresas? De fato, o que é a tal responsabilidade social dos empresários? Onde ela está? Além disso, em geral o olhar ainda é para o problema: precisamos fazer "projetinhos" para que os jovens não se envolvam com a criminalidade. Acho totalmente questionável isso. Onde estão os direitos?

Quando se trata de emprego, evidente que o grande desafio é o crescimento do país e a geração de novos postos de trabalho, o que está colocado para todas as gerações. Especificamente no caso dos jovens, penso que é importante começar a pensar em saídas para esse grupo, considerando o trabalho, a educação como direitos e não como uma forma de controle. Além disso, acredito ser importante, quando se trata da formulação de uma política, ouvir e chamar à participação os atores envolvidos. De modo geral, constatamos que boa parte das ações públicas no Brasil é elaborada e implementada sem considerar os desejos, as expectativas e as necessidades dos atores. No caso dos jovens, isso se repete.

Juliana - Quais são as principais visões ou concepções de juventude que estão presentes nessas intervenções hoje e na sociedade de uma forma geral?

Maria Carla - Acho que têm predominado duas visões principais de juventude em diferentes programas ou projetos: o jovem como problema ou o jovem como solução. Vejo limitações em ambas. No caso dos programas que visam combater o desemprego juvenil, por exemplo, é muito comum a justificativa concentrar-se em torno do olhar para o jovem como problema. Por exemplo: a idéia de que é preciso gerar alternativas de trabalho e renda para jovens para que os jovens não se envolvam com o crime. Ora, desse modo não estaríamos considerando o trabalho como um direito das jovens gerações, mas como uma forma de combater a violência... Em relação à perspectiva do jovem como solução, a idéia posta em muitos programas é a de que os jovens são os principais atores do desenvolvimento. Onde estaria a responsabilidade dos adultos? Nesse caso, é colocado um peso enorme nos ombros dos jovens.

Acredito sobretudo na perspectiva dos jovens como sujeitos de direitos. Quando pensamos nas questões do trabalho, também é importante perceber o trabalho como um direito dos jovens e, quando falo em trabalho, não estou compreendendo apenas o trabalho assalariado. A perspectiva é mais ampla, assim como o direito à educação, ao lazer, à cultura, ao tempo livre. 
Juliana - Que propostas você faria a respeito de como lidar com a questão do trabalho para os jovens hoje?

Maria Carla - Acho que seria importante buscar diferentes alternativas combinadas à própria trajetória juvenil. Para um jovem que ainda não completou o ensino fundamental, o essencial é que ele complete sua escolaridade, que possa receber uma renda para fazê-lo. Isso já foi feito por exemplo na cidade de São Paulo, por meio do Programa Bolsa-Trabalho. O problema é que ali havia um desencontro muito grande em relação à perspectiva de muitos jovens - queriam profissionalização e emprego enquanto o Estado oferecia bolsa. A idéia de redistribuir renda para que ele retomasse sua trajetória escolar era excelente, mas o tempo foi muito curto para que isso acontecesse de fato. Ao mesmo tempo, o que fazer com o desejo ou necessidade desses jovens de trabalhar? O que podemos apresentar a eles? Além disso, para os jovens que já completaram o Ensino Médio ou o Ensino Superior, certamente deveriam ser pensadas outras alternativas. Eles também têm enfrentado problemas de inserção no mercado de trabalho. Nos vários debates em que estive, muitos com a presença de diferentes jovens, é muito forte o desejo por um trabalho estável, com registro em carteira, o que está cada vez mais difícil. Querem um trabalho decente. Mas o que estamos fazendo para isso? Outros também desejam um trabalho vinculado à possibilidade de transformação e desenvolvimento de seus locais de moradia, como trabalho social remunerado e não voluntário. Daí emergem propostas de trabalho em diferentes áreas, a partir de atividades já desenvolvidas ou com possibilidade de desenvolverem-se em seus contextos (saúde, cultura, meio ambiente, turismo, comunicação, dentre outros). $\mathrm{O}$ apoio ao trabalho associativo e cooperativo, a formação empreendedora, o acesso ao crédito; e no meio rural, a garantia do acesso à terra, o apoio à agricultura familiar, ao artesanato local, o turismo rural, dentre outras alternativas que não se restringissem ao trabalho agrícola também foram objetos de debate. Em todos esses casos, é importante perceber se essas alternativas estão de fato permitindo o alargamento das perspectivas profissionais desses jovens. Acho que também fala-se pouco da necessidade de diminuição da jornada de trabalho, da necessidade de uma rigorosa fiscalização e controle nos diversos ambientes de trabalho, da criação de meios mais efetivos de apoio e acompanhamento do jovem na construção de suas trajetórias no mundo do trabalho e no mundo da educação, o que tem sido reivindicado por muitos deles.

Juliana - Para enfrentar os desafios que estão postos, qual configuração de parcerias você acha que é necessária, com que responsabilidades?

Maria Carla - Todos têm responsabilidades de diferentes ordens. Há algo mais amplo que se relaciona com a retomada da trajetória de crescimento econômico e geração de empregos, na redução da taxa de juros, investimento em educação e pesquisa e redistribuição de renda, que são tarefas do Estado. Os empresários também têm responsabilidade nessa retomada do crescimento: Precisam investir menos no mercado financeiro, que não gera empregos, e mais na produção e no desenvolvimento de novos produtos. Nesse último aspecto, a universidade também tem um papel fundamental. Especificamente no caso dos jovens, acho que o Estado poderia contribuir no sentido da redistribuição de renda direta para jovens de baixa escolaridade, na criação de empregos públicos para jovens, por exemplo. A França e a Itália fizeram isso. Talvez não precisemos seguir o mesmo modelo, mas uma demanda crescente é a de que os jovens possam tornar-se agentes culturais, por exemplo, e serem contratados para isso. E quando digo contrato, não me refiro apenas a receber uma bolsa, mas conseguir construir uma perspectiva de desenvolvimento profissional a partir disso. Além disso, há muitos grupos juvenis em ação que poderiam receber apoio técnico e financeiro para a realização de suas atividades. Acho também que o Estado precisa controlar mais o tipo de trabalho que é realizado pelos jovens. Muitas vezes, um estagiário, por exemplo, vira "escraviário", como dizem muitos jovens. Há pouco acompanhamento efetivo disso. E uma vez que sabemos que não haverá emprego assalariado para todos, que outras alternativas podemos pensar? 
E as escolas? Discutem trabalho com os jovens? Há um tremendo abismo entre a escola e o mundo do trabalho. A escola poderia ser um espaço fundamental para essa discussão. Aliás, eu diria que as universidades, de modo geral - evidentemente devem existir exceções - fazem muito mal isso. Preocupam-se essencialmente com a formação e, quando o aluno termina o curso, é um "salve-se quem puder".

A sociedade civil também pode e vem tomando iniciativa. Há muitas associações, ONGs e movimentos tentando responder a esse desafio. Mas no caso das ONGs, por exemplo, o problema é ficar fazendo projetos aqui e ali, que resolvem o problema de alguns poucos, e não pressionar o Estado a encontrar saídas. Não adianta apenas fazer um projeto muito interessante, mas não tentar interferir no campo das políticas públicas. E as empresas? Muitas vezes financiam pequenos projetos em bairros pobres, mas não olham para seus próprios funcionários, não geram empregos para jovens ou submetem jovens trabalhadores a péssimas condições de trabalho e com poucas condições de desenvolvimento profissional.

Por fim, acho que aos próprios jovens também cabe pressionar, reivindicar, criar e alguns grupos já estão fazendo isso de algum modo.

Juliana - Como você acha que a universidade poderia contribuir para essa discussão? Quais os temas que ainda precisam ser mais explorados pelas pesquisas?

Maria Carla - Como já disse, numa perspectiva mais ampla, pressionar para que haja possibilidade de investir mais em pesquisas, para que sejam desenvolvidos novos produtos que possam contribuir para a geração de novos empregos, oferecer apoio técnico a pessoas e grupos que estão investindo em novas alternativas de trabalho, tais como o trabalho cooperativo, por exemplo. As incubadoras de diferentes universidades já fazem isso, mas acho que poderiam fazer muito mais. Além disso, é seu papel compreender melhor a relação específica dos jovens com o mundo do trabalho. Embora a questão do desemprego juvenil tenha se destacado na agenda pública desde o final dos anos 90 , há pouca produção de conhecimento em torno disso. O mesmo pode-se dizer sobre a relação dos jovens com o trabalho nos mais diferentes setores econômicos. Também pouco se sabe sobre os impactos das políticas que vêm se desenvolvendo. Nesse campo, eu diria que há ainda quase tudo por fazer. Vimos avanços significativos nos estudos sobre gênero e trabalho nos últimos anos, mas muito menos debate em torno da temática geração e trabalho. 